\title{
Implantação de horto medicinal nas Faculdades Nova Esperança como instrumento de promoção de saúde e qualidade de vida
}

\author{
Implantation of medical housing at Faculdades Nova Esperança as na instrument for health \\ promotion and quality of life \\ Implantación de vivendas medicinales em Faculdades Nova Esperança como instrumentos de \\ promoción de la salud y calidad de vida
}

\section{Resumo}

As plantas com fins medicinais são parte da grande biodiversidade, e estão introduzidas na vida da população desde os tempos mais remotos e que pode ser utilizado para curar um mal devido a sua grande importância fitoterápica, baixo custo e fácil acesso. O consumo de produtos fitoterápicos aumenta constantemente, bem como os costumes e princípios que foram passados de geração em geração. Foi por base em tais fatores que o presente trabalho trata-se do projeto de implantação do horto de plantas medicinais das Faculdades Nova Esperança que com objetivo de manter exemplares vivos de plantas medicinais, difundir os conhecimentos científicos acerca dos princípios ativos presentes nessas plantas, tendo em vista que o uso incorreto desses fitoterápicos pode acarretar não a melhora, mas a piora da saúde de quem os utiliza, além de desenvolver ações educativas através de palestras, cartilhas, oficinas e doação de mudas terapêuticas utilizando material reciclável. O horto de plantas medicinais foi implantado na Fazenda Escola da Instituição no ano de 2019, contando com 30 espécies de plantas medicinais, e está sendo utilizado como instrumento de aprendizagem na formação dos alunos, visando o uso da fitoterapia como prática de saúde preventiva, curativa e terapêutica, agregando incentivo ao cultivo e consumo correto dessas espécies vegetais tão importantes.

Palavras-chave: Plantas medicinais; Horto medicinal; Fitoterapia.

\begin{abstract}
Plants with medicinal purposes are part of the great biodiversity, and are introduced in the life of the population since the most remote times and can be used to cure an illness due to their great phytotherapeutic importance, low cost, and easy access. The consumption of herbal products is constantly increasing, as are the customs and principles that have been passed down from generation to generation. It was based on these factors that the present work is the project for the implementation of the medicinal plants garden at Faculdades Nova Esperança, which aims to maintain living examples of medicinal plants, to spread scientific knowledge about the active principles present in these plants, considering that the incorrect use of these herbal medicines can cause not the improvement, but the worsening of the
\end{abstract}


health of those who use them, in addition to developing educational activities through lectures, booklets, workshops, and donation of therapeutic seedlings using recyclable material. The medicinal plant garden was implemented in the Farm School of the Institution in 2019, with 30 medicinal plant species, and is being used as a learning tool in the formation of students, aiming at the use of phytotherapy as a preventive, curative, and therapeutic health practice, adding incentive to the cultivation and correct consumption of these important plant species.

Keywords: Medicinal plants; Medicinal garden; Phytotherapy.

\section{Resumen}

Las plantas con fines medicinales forman parte de la gran biodiversidad, y están introducidas en la vida de la población desde los tiempos más remotos y que pueden ser utilizadas para curar una dolencia debido a su gran importancia fitoterapéutica, su bajo coste y su fácil acceso. El consumo de productos fitoterapéuticos aumenta constantemente, así como las costumbres y los principios que se han transmitido de generación en generación. Con base en estos factores, el presente trabajo trata del proyecto de implementación del jardín de plantas medicinales de Faculdades Nova Esperança, que tiene como objetivo mantener vivos ejemplares de plantas medicinales, difundir el conocimiento científico sobre los principios activos presentes en estas plantas, considerando que el uso incorrecto de estas hierbas medicinales puede causar no la mejora, sino el empeoramiento de la salud de quienes las utilizan, además de desarrollar acciones educativas a través de conferencias, folletos, talleres y donación de plantones terapéuticos utilizando material reciclable. El jardín de plantas medicinales fue implementado en la Granja Escuela de la institución en 2019, con 30 especies de plantas medicinales, y está siendo utilizado como herramienta de aprendizaje en la formación de los estudiantes, apuntando al uso de la fitoterapia como práctica de salud preventiva, curativa y terapéutica, sumando el incentivo al cultivo y consumo correcto de estas importantes especies vegetales.

Palabras clave: Plantas medicinales; Jardín medicinal; Fitoterapia.

\section{Introdução}

Historicamente o homem vem utilizando as plantas como uma das principais fontes alimentícias, econômica, lucrativa e medicinal em que a escolha da planta se baseava na intuição e analogias a fim de tratar e curar diversas enfermidades, sendo aplicadas por diversos grupos étnicos e culturas populares. Para garantir sua sobrevivência à medida que o tempo ia passando, o homem encontrou nas plantas uma aliada, utilizando-as como fonte terapêutica e este fato é observado desde os tempos mais remotos até os dias atuais (Viegas-júnior, Bolzani \& Barrero, 2006; Bevilacqua, 2010).

Desde 2005, o Conselho Nacional de Saúde aprovou a utilização de plantas medicinais e fitoterápicos na Política Nacional de Práticas Integrativas e Complementares do Sistema Único de Saúde (SUS), visto que, o u so de plantas medicinais em suas diferentes formas farmacêuticas, incentiva o desenvolvimento comunitário, a solidariedade e a participação social (Brasil, 2006a). A ampliação das opções terapêuticas ofertadas aos usuários do Sistema Único de Saúde, com garantia de acesso às plantas medicinais e serviços relacionados à fitoterapia, com segurança, eficácia e qualidade, na perspectiva da integralidade da atenção à saúde, é uma importante estratégia com vistas à melhoria da atenção à saúde da população e à inclusão social (Brasil, 2006b). Segundo a Organização Mundial da Saúde (OMS), planta medicinal é todo vegetal que contém, em um ou vários de seus órgãos, substâncias que podem ser empregadas para fins terapêuticos ou precursores de substâncias utilizadas para tais propósitos (Oms, 2002).

As plantas medicinais sempre estiveram presentes na vida da humanidade, influenciadas pela sabedoria indígena e pela tradicionalidade chinesa, que as utilizou como forma preventiva e curativa de doenças. Apesar dos avanços tecnológicos e das terapias farmacológicas modernas, o uso das ervas medicinas ainda é frequente, devido à tradição, ao baixo custo e ao fácil acesso (Brasil, 2016b).

Estudos sobre a medicina popular vêm merecendo importância cada vez maior devido ao contingente de informações produzidas pela ciência e a retomada do uso de medicamentos de origem vegetal, na forma de chás, decoctos e tinturas, auxiliando no tratamento e profilaxia de doenças, ao lado da terapêutica convencional (França, Souza, Baptista \& Brito, 2008). A inclusão de plantas medicinais e fitoterápicos é favorável a saúde humana desde que o usuário tenha conhecimento da finalidade, riscos e benefícios, portanto, o profissional de saúde deve considerar esse cuidado popular, viabilizando uma atenção singular, centrada nos valores, crenças e estilo de vida das pessoas (Badke, 2011). 
Como consequência do crescente uso de plantas medicinais pela humanidade, pesquisadores nas áreas de Botânica, Fitoquímica e Etnofarmacologia se empenham cada vez mais em estudos das composições química e ação biológica dessas plantas que são de grande importância, tendo em vista que $80 \%$ da população mundial fazem uso das plantas e seus derivados nos seus cuidados com a saúde (Mahomoodally; \& Seebaluck, 2013).

Diante deste quadro, é de relevância fundamental destacar a aplicabilidade e importância da nossa flora medicinal sobre o ponto de vista tradicional, cultural, social, científico e tecnológico, como também solidificar a valorização de nossa diversidade ambiental (Mendes, Gonzalez \& Sampaio, 2010). É imprescindível promover o resgate, o reconhecimento e a valorização das práticas tradicionais e populares de uso de plantas medicinais e remédios caseiros, como elementos para a promoção da saúde, conforme preconiza a Organização Mundial da Saúde (Azevedo \& Moura, 2010).

A implantação do Horto de Plantas Medicinais visa o uso da fitoterapia como prática de saúde preventiva, curativa, terapêutica, agregando outros fatores como o incentivo ao cultivo e consumo de plantas medicinais. Através do cultivo, manuseio e manutenção das plantas medicinais, é favorecido o bem-estar e desenvolvido um processo de vivências, pesquisa, autoformação e construção coletiva (Matos, 2007).

De acordo com Paulo Freire (2000), a conjuntura da saúde no Brasil revela a desigualdade social como um dos fatores que impedem o acesso à saúde. Sabe-se que as plantas medicinais, apesar de sua eficácia, ainda confrontam com os mecanismos sociais de valorização das indústrias farmacêuticas (Mostardeiro, 2014). Por outro lado, o crescente aumento dos preços dos medicamentos industrializados e o modismo mundial recente de consumo de produtos considerados in natura, despertou o interesse pela finalidade curativa das plantas, atribuída à sua diversidade de espécies vegetais e biomas, e riqueza étnico-cultural no Brasil (Ethur et al. 2011).

Faz-se necessária a realização de estudos capazes de identificar como a fitoterapia tem sido praticada nas comunidades atendidas pelo SUS atualmente. Esses estudos visam obter dados que permitam avaliar a coerência entre o que tem sido praticado pela comunidade e o uso seguro das plantas medicinais no tratamento primário à saúde, conforme recomendado na literatura e com base em estudos científicos e fontes confiáveis (Araújo, Araújo, Freitas, Ferreira, 2014).

Neste contexto o Horto de Plantas Medicinais assume um papel fundamental no auxílio do tratamento de doenças, contribuindo com a preservação do meio ambiente e do conhecimento e da tradição no uso popular das plantas. Pedagogicamente, a interface com a graduação, pesquisa e extensão, faz do horto um instrumento de aprendizagem e colaboração na formação dos alunos. Propôs desenvolver e vivenciar novos hábitos e costumes, trabalhando a medicina popular e criando canais de acesso com baixo custo e eficácia. O horto é um local de estudo, pois propicia uma forma das pessoas se reunirem para trocar ideias ou experiências, contribuindo para que todos aprendam as formas de propagar ou cultivar as plantas. Os acadêmicos participantes foram instrumentalizados para passar essas orientações com mais segurança, possibilitando um processo de ensino-aprendizagem dinâmico e significativo.

O Horto de Plantas Medicinais assume um papel de grande importância social, sendo fundamental no auxílio do tratamento de doenças, contribuindo com a preservação do meio ambiente e do conhecimento e da tradição no uso popular das plantas. A interação com a graduação e a extensão, faz do horto um instrumento de aprendizagem e colaboração na formação dos alunos da instituição.

\section{Metodologia}

O projeto Horto é de abordagem qualitativa e trata-se de um relato de experiência, como considera Pereira et al. (2018) e foi realizado pelos acadêmicos do curso de farmácia e agronomia participantes do Programa de Iniciação Científica e de Extensão da FACENE/FAMENE (PROICE - FACENE/FAMENE) junto ao Instituto de Pesquisa em Fármacos e Medicamentos (IpeFarM-UFPB), do qual foram obtidos mudas de plantas medicinais, sendo possível à implantação do horto 
na Fazenda Escola da FACENE/FAMENE. o desígnio é contribuir com o conhecimento e disseminação da informação sobre o preparo, as formas de utilização das plantas e majoritariamente o uso racional desses fitoterápicos para a comunidade.

\section{Descrição da Experiência e Discussão}

As atividades foram realizadas através de um conjunto de ações e estratégias, que se desenvolveram durante os meses de março a dezembro de 2019 e 2020 em dias letivos normais de segunda a sexta.

Os discentes graduandos da FACENE foram os atores no desenvolvimento das atividades propostas. Sob orientação foi realizada revisão da literatura e uma lista contendo as plantas cultivadas no horto, contendo o nome científico, nome popular e uso medicinal. O cultivo, então, foi realizado na Fazenda Escola da instituição em uma área $100 \mathrm{~m}^{2}(10 x 10 \mathrm{~m})$ com os recursos já disponíveis, facilitando a implantação do projeto. Na Fazenda Escola foram cultivadas 30 espécies de plantas, dentre elas: Cymbopogon citratus (capim santo), Sambucus nigra (sabugueiro), Cymbopogon nardus (citronela), Cynara scolymus (alcachofra), Cissampelos sympodialis (milona), Melissa officinalis (erva cidreira), Phyllanthus niruri (quebra pedra), Plectranthus barbatus (boldo), Aloe vera (babosa), Mentha piperita (hortelã pimenta) e Zingiber officinale (gengibre).

Foram realizadas visitas a comunidade e postos de saúde próximos a FACENE, onde foi discutido sobre a possibilidade de visitas previamente agendadas dos moradores e usuários ao horto, bem como de atividades e informativos relacionados ao uso de plantas medicinais com este público.

A importância de cada planta a ser trabalhada, foi demonstrada através de cartazes, banners, elaboração de vídeos, exposição da planta fresca e postagens no instagram do Projeto procurando-se mostrar que o consumo é importante devido a diversos benefícios decorrentes. Adicionalmente, foram apresentados aspectos da planta, como morfologia, época de frutificação, formas de cultivo ou de ocorrência natural.

A finalidade desse projeto, quanto às famílias e as crianças participantes do mesmo é orientá-los sobre o uso correto de plantas medicinais durante as visitas domiciliárias e ao horto, relacionando sempre a saúde de forma geral. Em relação aos acadêmicos inseridos, o objetivo deste projeto é instrumentalizar os mesmos para que estejam sempre aptos a orientar as famílias durante as palestras e visitas ao horto.

\section{Discussão}

Trata-se de um relato de experiência, como considera Pereira et al. (2018) e foi realizado pelos acadêmicos do curso de Farmácia e Agronomia, participantes de um Programa de Iniciação Científica e de Extensão das Faculdades Nova Esperança, João Pessoa-PB, que tem como coordenadora a professora Élida Batista Vieira Sousa Cavalcanti e como colaboradora a professora Maria Denise Leite Ferreira.

Sobre a prática de implementação de um Horto Medicinal em um terreno da Fazenda Escola da FACENE/FAMENE, com uma área de $100 \mathrm{~m}^{2}$ (10x10m) e nos Centros de Saúde Nova Esperança, na cidade de João Pessoa-PB, o desígnio é contribuir para a produção de conhecimento e informações sobre as relações e práticas cotidianas no manuseio, manutenção e cultivo de plantas e ervas medicinais, mantendo exemplares vivos de plantas medicinais, a fim de ter aplicações didáticas, no processo ensino-aprendizagem, as várias disciplinas da Instituição, disseminando práticas educativas e reflexivas, agroecológicas e ambientais.

Outro objetivo é difundir os conhecimentos científicos acerca dos princípios ativos das plantas e ervas medicinais, contribuindo com o conhecimento das plantas medicinais para alunos da graduação e moradores da comunidade, com intuito de desenvolver as atividades de orientações e servir de referência no aprofundamento do conhecimento sobre plantas 
medicinais dos acadêmicos participantes do projeto de extensão buscando a orientação dos integrantes da comunidade quanto ao uso de plantas medicinais.

Além disso, desenvolver ação educativa junto aos Centros de Saúde Nova Esperança-Comunidade e, possivelmente, doação de mudas terapêuticas utilizando material reciclável; catalogar os saberes da comunidade e integrá-los ao processo de socialização; desenvolver manuais e métodos pedagógicos para propagar os conhecimentos científicos e populares presentes na medicina popular alternativa; desenvolver numa perspectiva dialógica com a comunidade, uma pedagogia fraterna e ecossistêmica que desperte o cuidado com o meio ambiente.

\subsection{Contato com grupos de idosos, gestantes e usuários da UBS orientando sobre o uso correto das plantas medicinais}

Em um primeiro contato, realizou-se rodas de conversa com o grupo de idosos e de gestantes das Faculdades Nova Esperança e com usuários da UBS Ipiranga, localizada no bairro de Valentina, onde foi explanada a importância do uso racional de fitoterápicos, bem como a troca de experiências sobre a vivência com plantas medicinais, sua aplicação terapêutica e manejo.

Os assuntos abordados na roda de conversas com os idosos foram plantas medicinais utilizadas na diabetes, hipertensão, dores intestinais e resfriados mostrando um banner (Figura 1), uma vez que essas patologias acometem ainda mais a terceira idade devido ao corpo não ter forças suficientes para combater essas enfermidades, a falta de atividade física, alimentação desregulada, relações emocionais, qualidade de vida, imunidade baixa, entre outros fatores agregam uma população idosa que apresentam alguma complicação. Neste viés, foi apresentado banners que continhas as informações da parte apropriada da planta à ser aproveitada, sua forma de preparo, bem como a finalidade terapêutica adequada baseado em pesquisas, a fim de que se possa conscientizar a população bem como incentivar o uso racional de plantas indicadas por um profissional.

Para tratamento da Diabetes, pode-se citar a Pata-de-vaca (Bauhinia forficata), espécie hipoglicemiante (antidiabética), cujas partes usadas são as folhas e caules. Pode ser utilizada por meio da infusão: 3g diárias, pó: 400mg, duas vezes ao dia e tintura: 20 a 30 gotas, três vezes ao dia. Outra também bastante utilizada é a Jambolão (Syzygium jambolanum (Lam.) DC) suas partes usadas são: cascas da árvore, folhas, semente e pode ser feito por decocção: 0,3g de pó das sementes secas em 150ml de água, 4 vezes por dia, tintura: 20 gotas em meio cálice de água, 3 vezes por dia e folhas, por infusão.

No caso de plantas usadas por hipertensos pode-se destacar os seguintes dados: Erva-cidreira (Melissa officinalis) promove um efeito relaxante nos vasos, semelhante ao bloqueio de cálcio no sistema cardiovascular. São usadas as folhas da planta por meio da infusão: entre 1 e 4 gramas de folhas da planta preferencialmente fresca para cerca de $150 \mathrm{ml}$ de água. Outra é o Chuchu (Sechium edule) os altos níveis de Potássio ajudam a equilibrar os efeitos do sódio, evitando assim a hipertensão. Partes usadas: folhas e frutos, feito por infusão e quantidade determinada por um profissional.

No tratamento de resfriados: Guaco (Mikania glomerata) é indicado como auxiliar no tratamento de afecções do trato respiratório, como tosses persistentes e tosses com expectoração. Pode ser feita despejando 1 xícara de chá de água fervente sobre 1 colher de sopa de folhas picadas. Abafe por 10 minutos e coe. Tome duas vezes por dia, também é comercializada em forma farmacêutica de xarope, administrar $5 \mathrm{ml}$, via oral, três vezes ao dia, de 8 em 8 horas. Também temos o: Limão siciliano (Citrus limon (L.) Burm.f.) as partes usadas são as folhas e frutos, e pode ser feita por decocção: 1 limão cortado e rodelas bem fervidas, 1 xícara 3 à 4 vezes ao dia, gargarejo: através do próprio suco.

E por último, no tratamento de dores intestinais: Hortelã-pimenta (Mentha $x$ piperita L.) com propriedades antiespasmódicas, que ajudam a aliviar as cólicas intestinais e a reduzir os gases. Parte da planta para uso: folhas e ramos são feitos por infusão: preparar $5 \mathrm{~g}$ de folhas e ramos frescos em uma xícara de água. Tomar quatro a cinco xícaras por dia. Também o Boldo (Plectranthus barbatus) sua parte utilizada são as folhas na preparação do infuso: feito com 3 a 4 folhas com 
água fervente, em quantidade bastante para uma xícara (de chá). Toma-se 1 a 3 xícaras do chá, adoçado ou não, opcionalmente. Assim, o uso de plantas medicinais assume grande valor na vida dos idosos, dando continuidade a essa prática de cuidado milenar com a saúde.

Figura 1: Banner apresentado para os idosos das Faculdades Nova Esperança sobre as plantas mais comumente utilizadas no tratamento da diabetes, hipertensão, dores intestinais e resfriados.

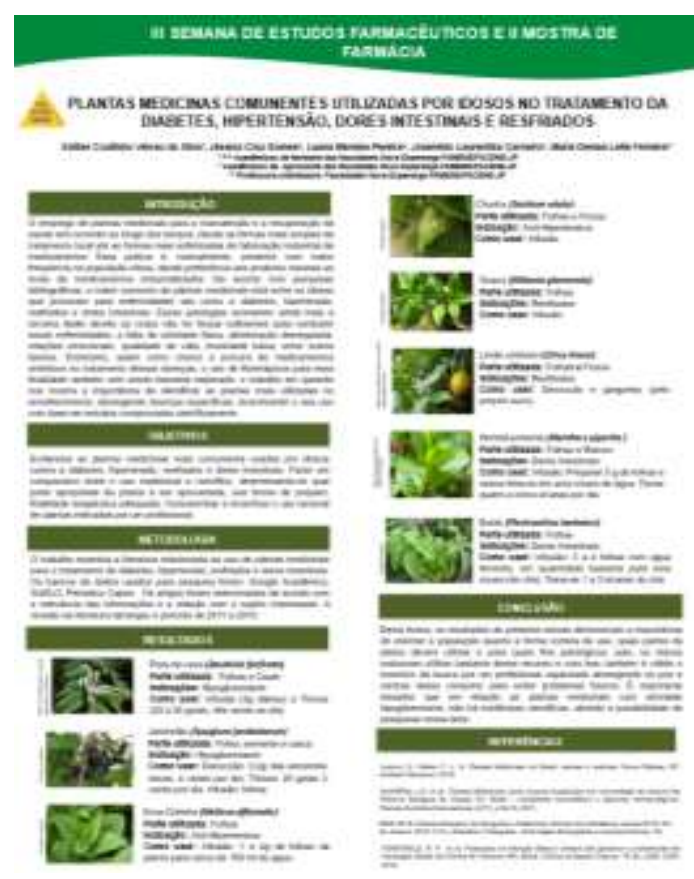

Fonte: Autores.

Os assuntos abordados nas rodas de conversas com o grupo de gestantes foram a respeito das plantas medicinais indicadas na gravidez, mostrando quais os benefícios das plantas medicinais, a fim de orientar as espécies permitidas na gravidez, à forma correta de preparo, a parte que deve ser utilizada e as advertências. A roda de conversa teve a apresentação de um banner como é mostrado na Figura 2. Pode-se destacar algumas espécies que são permitidas durante a gestação: Gengibre (Zingiber officinalis), indicada para o controle de vômitos e náuseas, seus óleos essenciais apresentam atividade antiemética, e seu rizoma pode ser consumido fresco ou como ingrediente de receitas culinárias. Framboesa (Rubus idaeus) pode ser ingerida a partir da $32^{\mathrm{a}}$ semana de gestação para auxiliar no trabalho do parto, através da infusão das folhas para extração de taninos e flavonoides. O Alho (Allium sativum) é um excelente antiviral e antibacteriano devido seus óleos voláteis sulfurados, sendo recomendado após o terceiro mês de gestação para a prevenção de anemia falciforme, utilizar o óleo, o macerado ou os dentes de alho in natura. A Castanha da índia (Aesculus hippocastanum) apresenta escina indicada após o primeiro trimestre da gestação para prevenção de edema nas pernas, atribuído a insuficiência venosa, utilizar na forma de cápsulas ou tintura. 
Figura 2: Banner apresentado para o grupo de gestantes das Faculdades Nova Esperança sobre o uso correto de plantas medicinais indicadas e contraindicadas na gravidez.

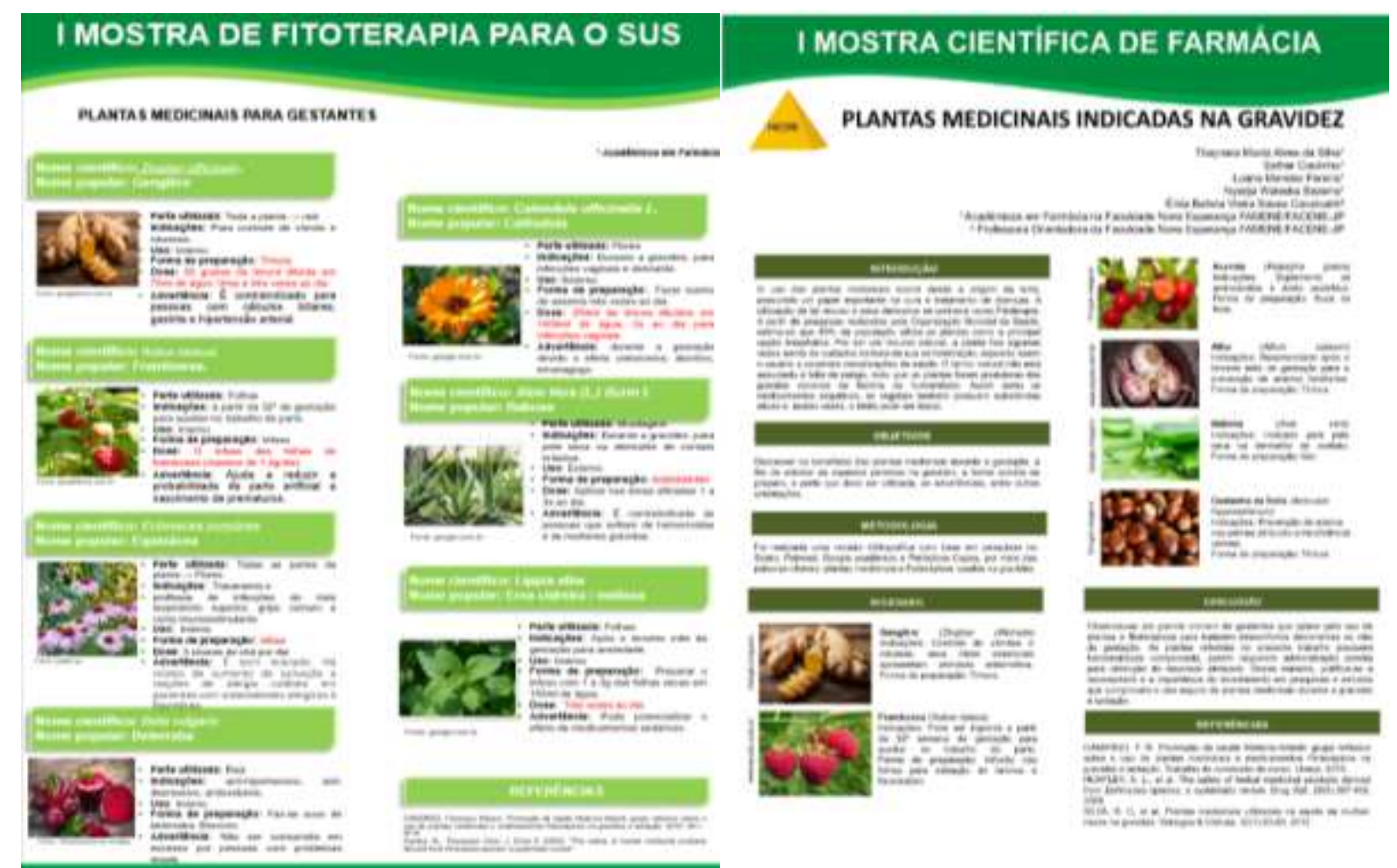

Fonte: Autores.

Os assuntos abordados nas rodas de conversas com os usuários da UBS do Ipiranga- Valentina foi a respeito das formas fitoterápicas caseiras ou remédios caseiros de plantas medicinais que são aqueles preparados em casa para fazer parte da alimentação ou para cura de algum mal que está prejudicando o bem-estar, sendo demonstrado na Figura 3 o banner que foi apresentado na roda de conversas, com o intuito de orientá-los a forma correta de diversas preparações de plantas medicinais.

As formas fitoterápicas são: nos banhos as ervas podem ser adicionadas a água e podem ser tratados tanto o corpo como um todo, ou apenas os pés e o rosto. O chá ou infuso é uma preparação obtida a partir da adição de água fervente sobre partes da planta seca ou fresca. O decocto ou cozimento consiste em cozinhar as partes da planta em água, deixando que sejam extraídos os seus constituintes químicos. Os emplastos consistem em socar a planta fresca até que se transforme em uma pasta. Após este processo, o preparado é colocado diretamente na área afetada e coberto com um pano limpo. O gargarejo é um método que consiste em remover o líquido com a ajuda do ar que se expulsa dos pulmões. A garrafada a planta deve ser picada e moída, colocada em recipiente fechado, guardada em um lugar fresco e ao abrigo da luz. A inalação é indicada para o tratamento de males respiratórios, descongestionando e ajudar na respiração. É um ótimo expectorante. Os lambedores são xaropes caseiros, obtidos a partir de ervas, água e açúcar ou mel. As tinturas são formas obtidas por maceração, utilizando um líquido de extração, como álcool de cereais, vinho ou vodka, com água. 
Figura 3: Banner apresentando para os usuários da UBS do Ipiranga sobre as formas fitoterápicas caseiras.

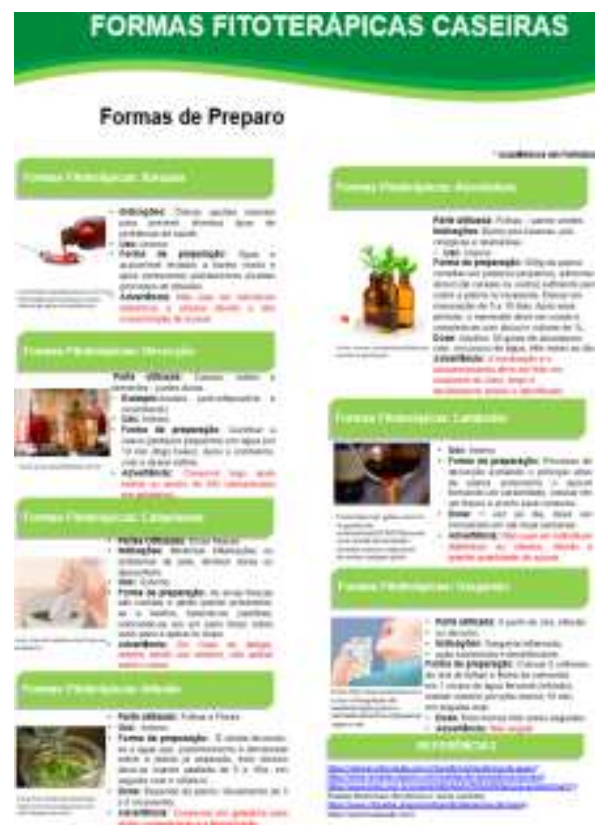

Fonte: Autores.

\subsection{Obtenção das mudas e implantação do horto na Fazenda Escola FACENE/FAMENE}

As mudas de plantas medicinais (Figura 4) foram obtidas no Instituto de Pesquisa em Fármacos e Medicamentos (IpeFarM-UFPB). Foi feita uma revisão da literatura e uma lista contendo as plantas cultivadas no horto, contendo o nome científico, nome popular e uso medicinal. Foram cultivadas cerca de 30 espécies de plantas, dentre elas: Cymbopogon citratus (capim santo), Sambucus nigra (sabugueiro), Cymbopogon nardus (citronela), Cynara scolymus (alcachofra), Cissampelos sympodialis (milona), Melissa officinalis (erva cidreira), Phyllanthus niruri (quebra pedra), Plectranthus barbatus (boldo), Aloe vera (babosa), Mentha piperita (hortelã pimenta) e Zingiber officinale (gengibre). O cultivo, então, foi realizado na Fazenda Escola da instituição (Figura 5) em uma área $100 \mathrm{~m}^{2}$ (10x10m) com os recursos já disponíveis, facilitando a implantação do projeto.

Figura 4: Mudas de plantas medicinais do horto na Fazenda Escola FACENE/FAMENE

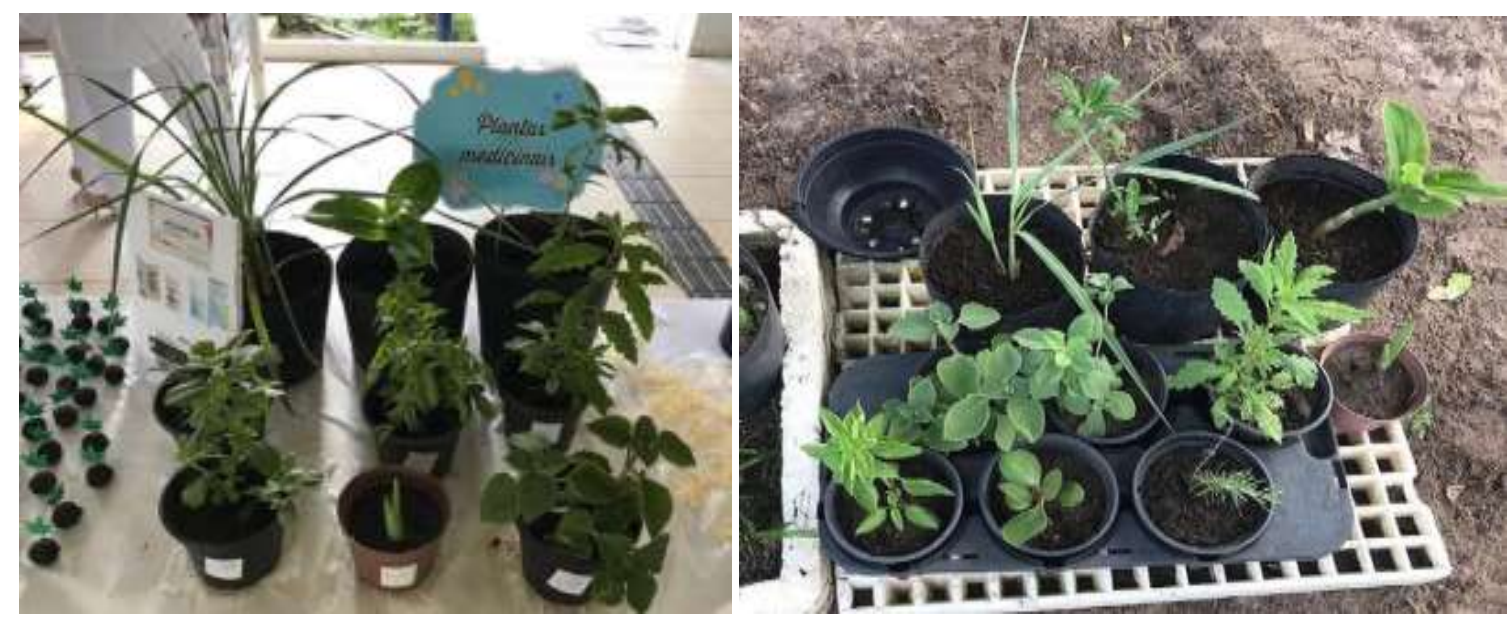

Fonte: Autores. 
Figura 5: Primeiro Horto Medicinal da Fazenda Escola das Faculdades Nova Esperança.
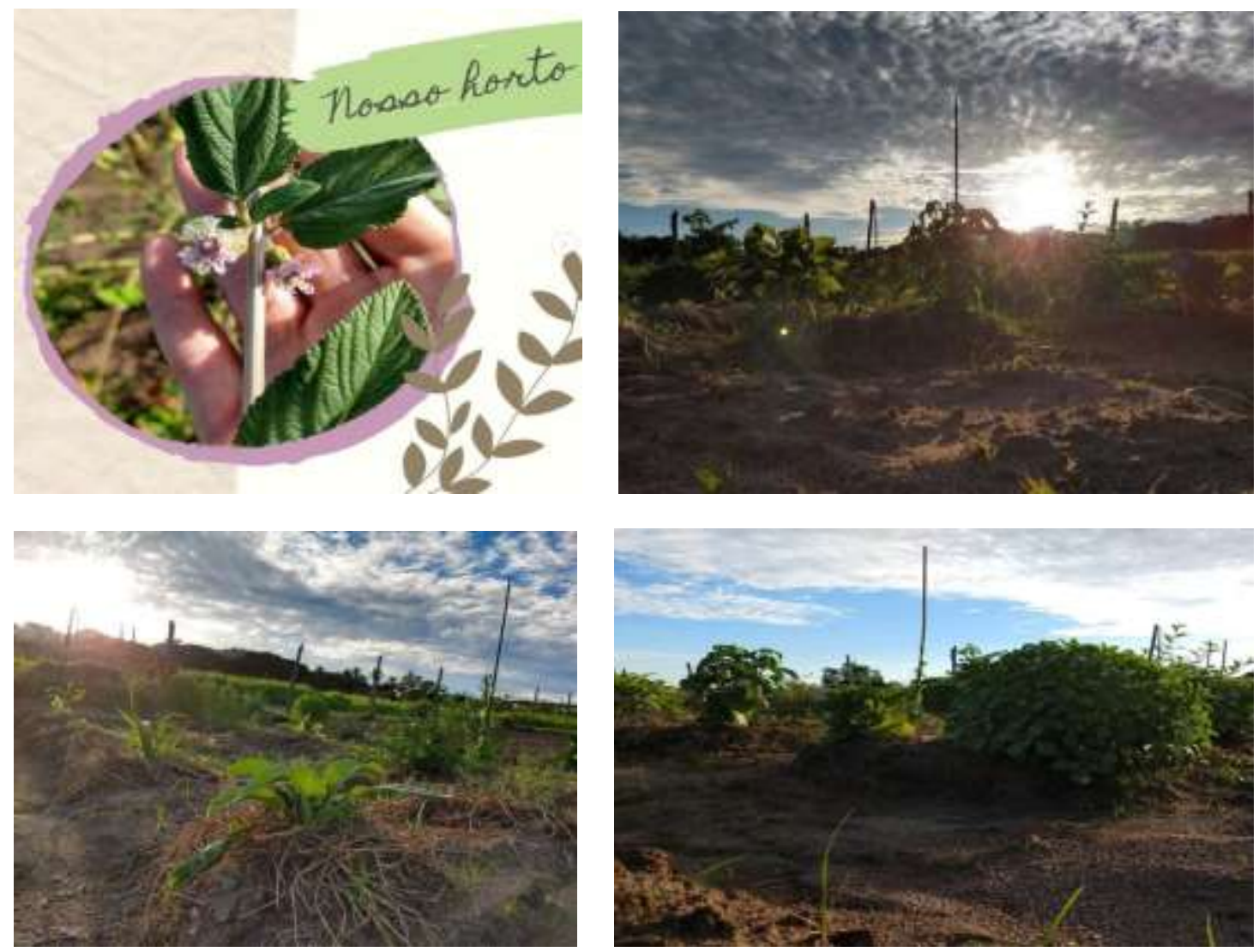

Fonte: Autores.

\subsection{Elaboração de velas ecológicas}

Durantes as reuniões, foi realizada a elaboração de velas ecológicas (Figura 6) com essência de citronela e lavanda para ser distribuído nas visitas técnicas.

Material básico:

- 1 porção de óleo de cozinha usado;

- $1 / 3$ de porção de estearina;

- Pavio corta-fogo para velas;

- Moldes: qualquer recipiente, desde que não seja afunilado em cima, como por exemplo, copos de vidro e formas de gelo. No projeto, utilizou-se vidros de penicilina.

Como preparar a mistura:

- Coar bem o óleo para tirar os resíduos;

- Misturar o óleo com a estearina e coloque numa vasilha própria para ir ao fogo;

- Ter cuidado para o líquido não ferver, pois é inflamável;

Preparação da vela:

- Separar o molde escolhido e medir nele a altura do pavio, do fundo até a borda;

- Nessa medida, segurar o pavio num prendedor de roupas;

- Retirar o pavio do frasco; 
- Derramar a mistura no frasquinho escolhido, somente até preencher a metade;

- Agora posicionar o pavio, novamente, bem no centro, apoiando o prendedor de roupas nas bordas;

- Aguardar esfriar por cerca de quatro horas;

- Retirar o prendedor de roupas com cuidado;

- Com uma tesoura, cortar o pavio, deixando uma sobra de aproximadamente $1 \mathrm{~cm}$ de vela.

Observações importantes:

- Para ter uma vela colorida e aromática, acrescentar corante e essência para velas depois da mistura básica estar pronta;

- Deixar no fogo por cerca de 20 minutos!

-

Figura 6: Elaboração de velas ecológicas para serem distribuídas para as gestantes, idosos e usuários da UBS.
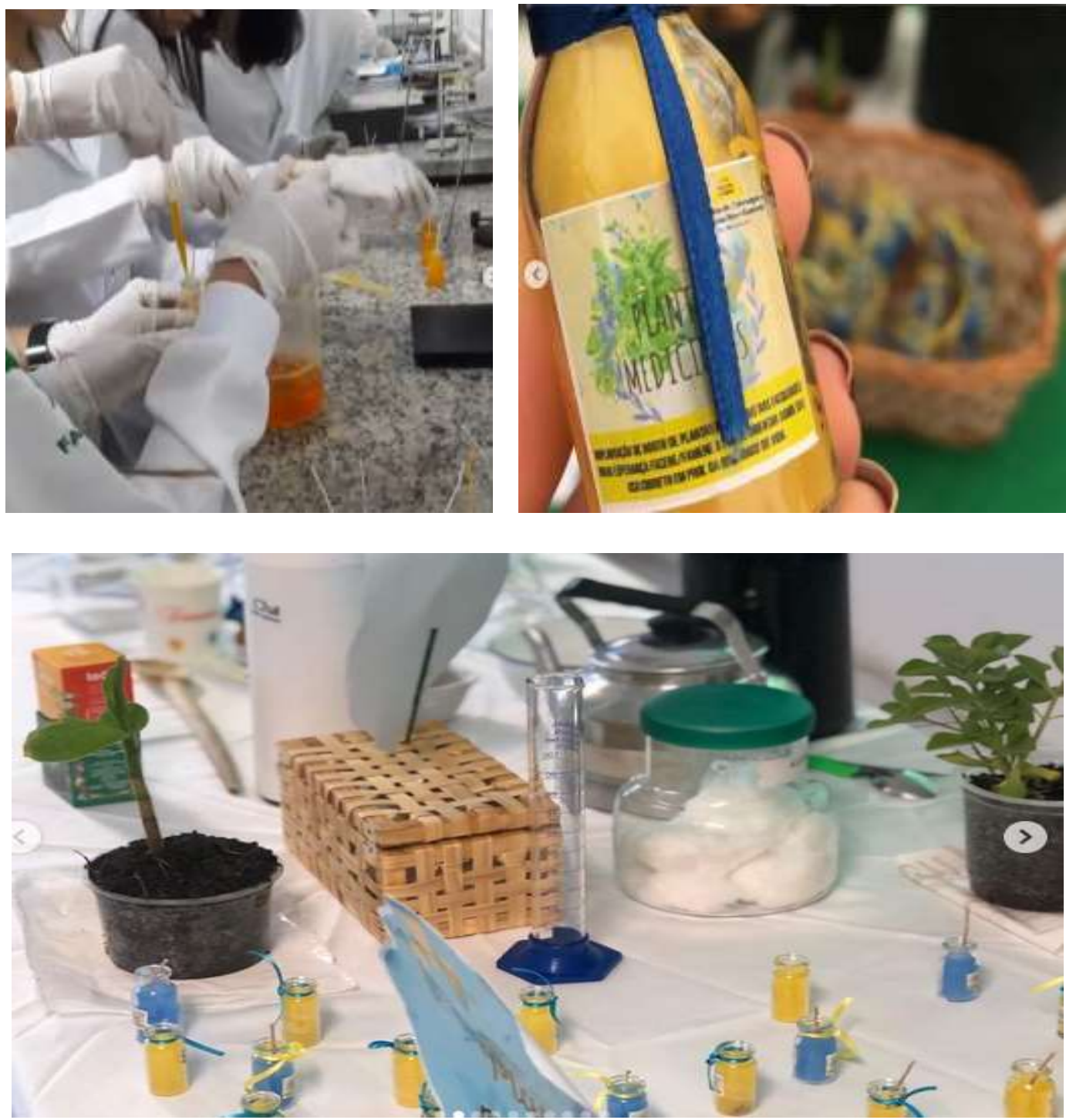

Fonte: Autores.

\subsection{Criação da cartilha de Plantas Medicinais}

A cartilha (Figura 7) foi elaborada pelos membros do Projeto de Extensão, a fim de orientar sobre seu uso correto em prol da qualidade de vida. Está cartilha é composta pela definição de plantas medicinais, toxicidade, intoxicação, Plantas 
Tóxicas, cuidados que devem ser tomados ao utilizar plantas medicinais, remédios caseiros (Formas fitoterápicas caseiras) e plantas utilizadas para a cura de males.

A cartilha foi distribuída nas rodas de conversas realizadas com os grupos de idosos e de gestantes das Faculdades Nova Esperança e com os usuários da UBS do Ipiranga- Valentina, com o objetivo de promover a saúde por meio da fitoterapia, contemplando o conhecimento popular, o reconhecimento etnobotânico das plantas, desde o seu plantio ao seu uso seguro e racional e visando sempre incentivar o plantio e o uso das plantas medicinais.

Figura 7: Cartilha sobre plantas medicinais.

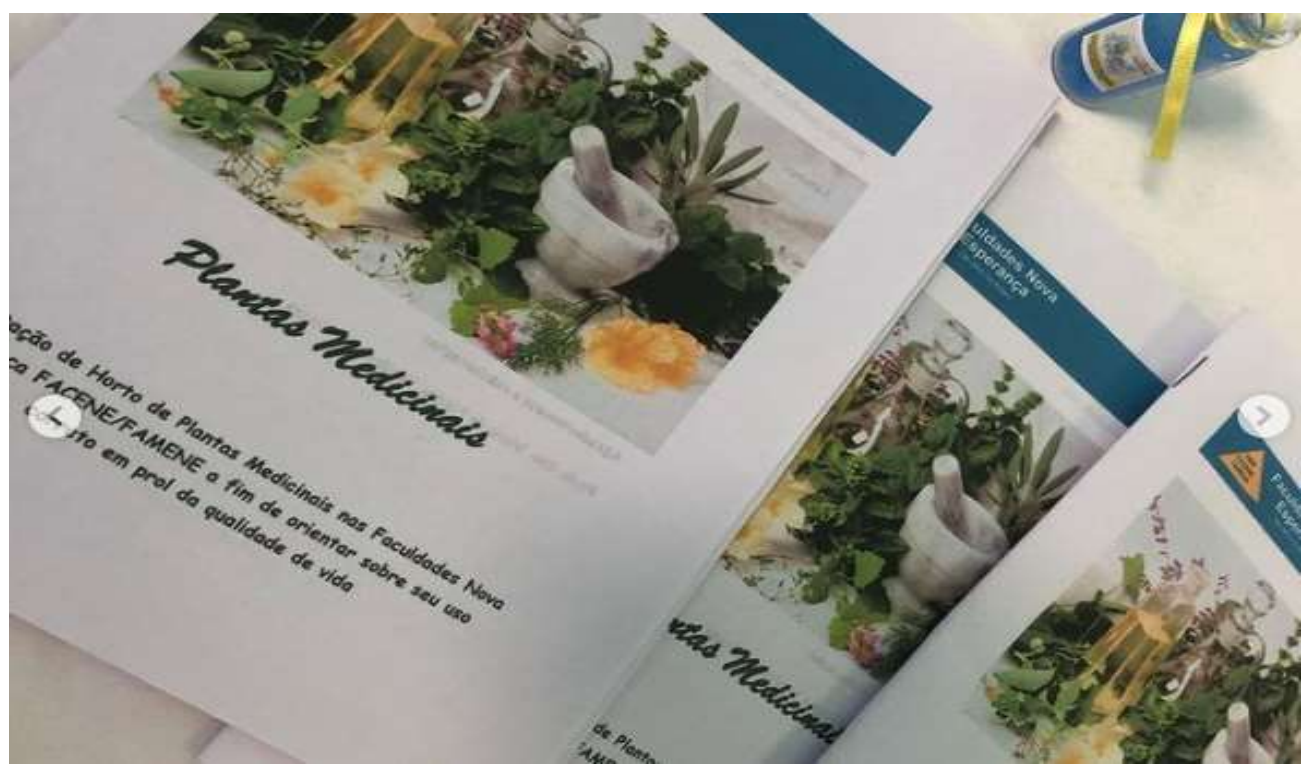

Fonte: Autores.

\subsection{Criação de posts acadêmicos}

O presente projeto de extensão tem o objetivo de manter exemplares vivos de plantas medicinais, difundir os conhecimentos científicos a cerca dos princípios ativos presentes nessas plantas e desenvolver ações educativas. Com isso, foram feitas postagens semanais sobre plantas medicinais na rede social do projeto (figura 8), contendo informações por escrito sobre indicações, contraindicações, toxicidade, formas de uso, além de vídeos sobre preparação correta de gel e chás de várias plantas medicinais.

O intuito era passar para o público alvo conhecimento sobre a importância, valorização e conservação de espécies de plantas medicinais, desde o cultivo, como também preservação e utilização para fins curativos, sobretudo no contexto da promoção de saúde e adoção de hábitos necessários à qualidade de vida e fortalecimento da consciência ambiental. 
Figura 8: Rede social do Projeto de Extensão

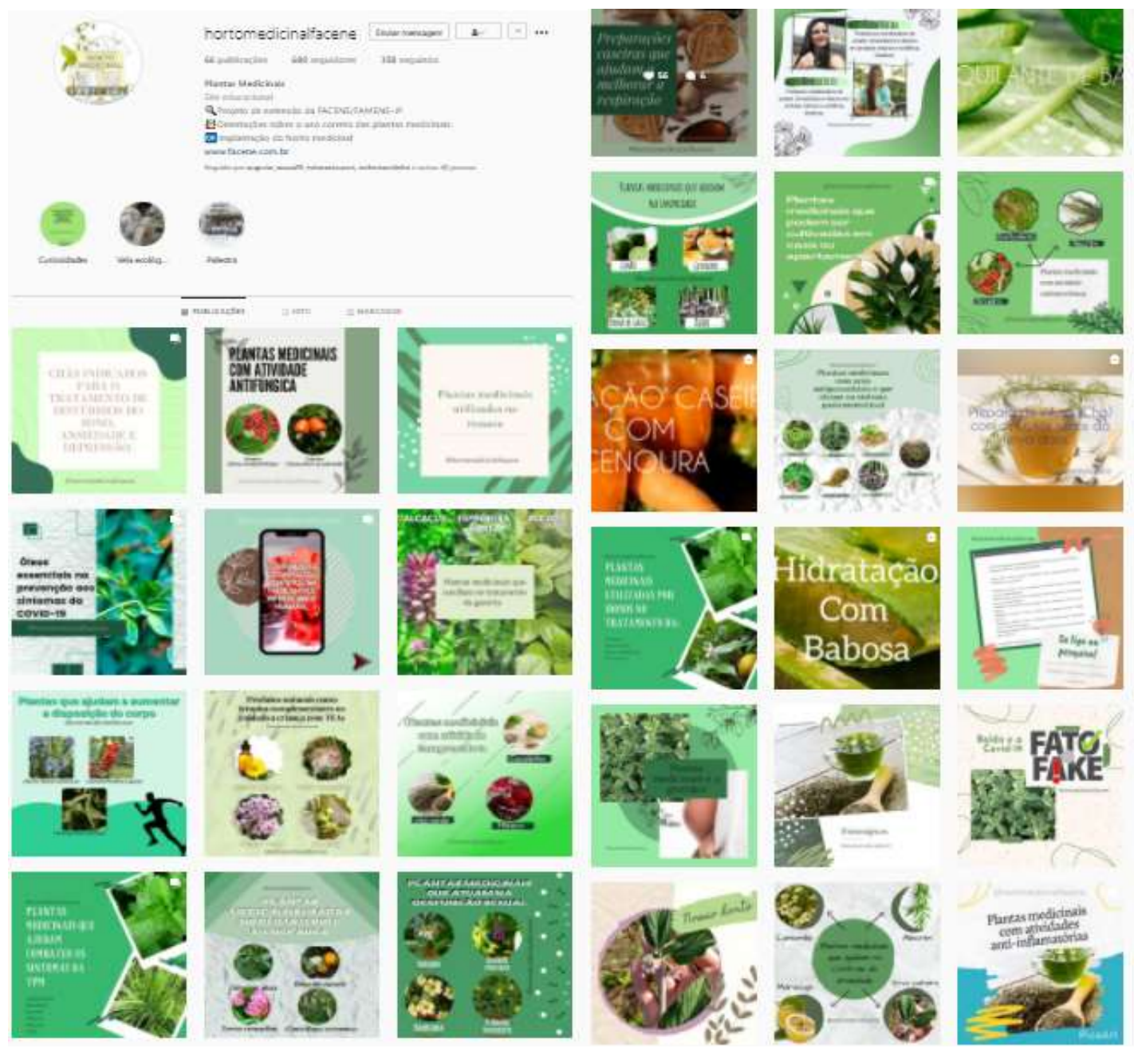

Fonte: Autores.

\section{Conclusão}

Os principais resultados obtidos foram o aumento do interesse e o fortalecimento da consciência dos estudantes acerca da importância das plantas medicinais. Os acadêmicos envolvidos no projeto desenvolveram várias habilidades, devido ao caráter multidisciplinar da proposta, integralizando as ciências agrárias com ciências da saúde, contribuindo não só para seu futuro profissional, mas também para a vida. Durante as visitas educativas para gestantes e idosos, foi observado o grande interesse por parte dos ouvintes, na qual pode-se compartilhar experiências a respeito da utilização de plantas para o uso medicinal, como também, compartilhar por meio de comprovações científicas as possíveis formas de utilização das plantas.

A implantação do horto medicinal também foi uma forma de incentivo para escolas, universidades e até mesmo Unidades Básicas de Saúde aderirem a ideia, pois além de proporcionar o aprendizado de conceitos científicos e de conhecimentos populares, podem estimular futuramente o envolvimento de alunos, famílias e até mesmo da comunidade no que se diz respeito a importância do conhecimento sobre plantas medicinais e contribui para o projeto de farmácias vivas, instituído pelo ministério da saúde no SUS. Sendo assim, os resultados apresentados nessa pesquisa nos fazem vislumbrar estudos futuros químicos e biológicos com as espécies do horto de plantas medicinais das faculdades Nova Esperança em prol da melhoria da qualidade de vida da comunidade. 


\section{Referências}

Azevedo, C. D. \& Moura, M. A. (2010). Cultivo de plantas medicinais: guia prático. Programa Rio Rural.

Araújo, F. J. E., Araújo, L. M. Y. D., Freitas. M. R. \& Ferreira, P. M. P. (2014). Aspectos toxicológicos da planta medicinal Casearia sylvestris Swartz: revisão de literatura. Rev Ciênc Farm Básica Apl. 35(3), 355-361.

Badke, M.R. (2011). Plantas medicinais: o saber sustentado na prática do cotidiano popular. Revista da Escola Anna Nery, 1, $132-139$.

Bevilacqua, H. G. C. R. (2010). Planejamento de horta medicinal e comunitária. Divisão Tec. Esc. Municipal de Jardinagem / Curso de Plantas medicinais. http://www.prefeitura.sp.gov.br/cidade/secretarias/upload/meio_ambiente/arquivos/plantas_med_web.pdf.

Brandão, H. N., Couto, R. D., David, J. M., David, J. P. \& Nascimento, J. A. P. (2010). Química e farmacologia de quimioterápicos antineoplásicos derivados de planta. Revista Química nova. 33(6), 1359-69.

Brasil. (2006a). Ministério da Saúde. Secretaria de Atenção à Saúde. Departamento de Atenção Básica. Política Nacional de Práticas Integrativas e Complementares no SUS - PNPIC-SUS.

Brasil. (2006b). Ministério da Saúde. Secretaria de Ciência, Tecnologia e Insumos Estratégicos. Departamento de Assistência Farmacêutica. Política nacional de plantas medicinais e fitoterápicos.

Camargo, F. R. (2015). Promoção da saúde Materno-Infantil: grupo reflexivo sobre o uso de plantas medicinais e medicamentos fitoterápicos na gravidez e lactação. Trabalho de conclusão de curso. Universidade Estadual Paulista, $38 \mathrm{f}$.

Ethur, L. Z. et al. (2011). Comércio formal e perfil de consumidores de plantas medicinais e fitoterápicos no município de Itaqui - RS. Revista Brasileira de Plantas Medicinais, 13(2), 121-28.

França, I. S. X., Souza, J. A., Baptista, R. S. \& Brito, V. R. S. (2008). Medicina popular: benefícios e malefícios das plantas medicinais. Revista Brasileira de Enfermagem, 2(61), 201-208.

Freire, P. (2000). Pedagogia da autonomia: saberes necessários à prática educativa. (15a ed.), Paz e Terra.

Huntley, A. L., Thompson, C. J. \& Ernst, E. (2005). The safety of herbal medicinal products derived from Echinacea species: a systematic review. Drug Saf, $28,387-400$.

IBGE. (2018). Instituto Brasileiro de Geografia e Estatística. Síntese de indicadores sociais 2018. 2018. 317p. (Estudos e Pesquisas - Informação demográfica e socioeconômica.

Lorenzi, H. \& Matos, F. J. A. (2018). Plantas Medicinais no Brasil: nativas e exóticas: Instituto Plantarum.

Matos, F. J. A. (2007). Plantas Medicinais: guia de seleção e emprego de plantas usadas em fitoterapia no nordeste do Brasil. UFC Edições. UFC.

Mendes, F. R., Gonzalez, F. G. \& Sampaio, P., S., P. (2010). Projeto santa horta no auxílio da identificação e conhecimento da fitoterapia através do cultivo de plantas medicinais. Revista Ceciliana, 2(2), 13-16.

Mahomoodally, M. F. \& Seebaluck, R. (2013) Current Practices towards the Use of Phytotherapy as Alternative Medicine in the Tropical Island of Mauritius. Journal of Medical Research and Development, 2(2), 35-41.

Mostardeiro, C. P. (2014). Avaliação das propriedades farmacológicas e farmacogenéticas do extrato e frações da planta Pavonia xanthogloea (Malvaceae), 2014. 138 p. Tese de Doutorado - Universidade Federal de Santa Maria (UFSM), Rio Grande Do Sul.

Oliveira, L.S. et al. (2011). Plantas Medicinais como recurso terapêutico em comunidade do entorno da Reserva Biológica do Tinguá, RJ, Brasil metabólitos secundários e aspectos farmacológicos. Revista Científica Internacional, 4 (17), 54-74.

Pereira A. S. et al. (2018). Metodologia da pesquisa científica. UFSM.

Silva, R. C. et al. (2012). Plantas medicinais utilizada na saúde da mulher: riscos na gravidez. Diálogos \& Ciência, 32(1), 20-28.

Viegas-junior, C., Bolzani, V. S., \& Barrero, E. J. (2006) Os Produtos Naturais e a química Medicinal Moderna. Química Nova, 29 (2), $326-337$. 